\title{
COMMENTARY
}

\section{When pressure does not mean volume? Body mass index may account for the dissociation}

\author{
Vito Fanelli, ${ }^{1,2,3}$ and V Marco Ranieri*3 \\ See related research by Mattingley et al., http://ccforum.com/content/15/1/R60
}

\begin{abstract}
Low tidal volume (VT $6 \mathrm{ml} /$ predicted body weight) pressure limited (plateau pressure $<30 \mathrm{CmH}_{2} \mathrm{O}$ ) protective ventilation as proposed by the ARDS Network was associated with an improvement in mortality and is considered the gold standard for acute respiratory distress syndrome (ARDS) ventilation strategies. Limiting plateau pressure minimizes ventilator-induced lung injury by reducing the trans-pulmonary pressure, which is the real alveolar distending pressure. However, in the presence of chest wall elastance impairment, as observed in obese patients, plateau pressure underestimates the trans-pulmonary pressure and derecrutiment at low distending pressure could occur. Moreover, low tidal volume to keep plateau pressure $<30 \mathrm{cmH}_{2} \mathrm{O}$ could be associated with large differences compared to measured total lung capacity. Quantitative bedside techniques that are able to measure lung volumes together with trans-pulmonary pressure could expand our chances to tailor mechanical ventilation in ARDS patients.
\end{abstract}

In the previous issue of Critical Care, Mattingley and colleagues [1] interestingly demonstrated that $6 \mathrm{ml} / \mathrm{kg}$ protective ventilation to keep a plateau pressure $\left(\mathrm{P}_{\text {plat }}\right)$ $<30 \mathrm{cmH}_{2} \mathrm{O}$ results in wide variation of tidal volume (VT) when compared to total lung capacity (TLC) in a mixed population of acute lung injury, acute respiratory distress syndrome (ARDS) and otherwise mechanically ventilated patients. Moreover, a positive relationship between lung volumes affected by body mass index (BMI) has been shown. The nitrogen wash-in and wash-out technique

\footnotetext{
*Correspondence: marco.ranieri@unito.it

${ }^{3}$ Department of Anestesia and Critical Care, Ospedale S. Giovanni BattistaMolinette, corso Dogliotti 14, 10126, University of Turin, Turin, Italy

Full list of author information is available at the end of the article
}

was used to measure functional residual capacity (FRC) and inspiratory capacity (IC) with a sustained inflation of $40 \mathrm{cmH}_{2} \mathrm{O}$ approaching TLC in 14 patients consecutively. In this patient population, a strong positive correlation was found between both FRC and TLC, and FRC and IC. The BMI was an important determinant enforcing this correlation. Moreover, the protective ventilation limiting $\mathrm{P}_{\text {plat }}$ of less than $30 \mathrm{cmH}_{2} \mathrm{O}$ resulted in a VT variation of 9 to $24 \%$ compared to observed TLC.

The interdependent combination of $\mathrm{VT}$ and positive end-expiratory pressure (PEEP) is the most significant determinant in perpetuating lung injury in ARDS patients [2]. Ventilator induced lung injury (VILI) may occur with both VT-inducing overdistension of aerated alveoli and low distending pressure allowing the alveoli to be recruited and derecruited [3,4]. Moreover, the synergistic combination between mechanical ventilation and innate immune response has been demonstrated to contribute to distal organ dysfunction $[4,5]$.

The ARMA study [6] unequivocally demonstrated that protective mechanical ventilation adopting a VT of $6 \mathrm{ml} /$ predicted body weight (PBW) versus $12 \mathrm{ml} / \mathrm{PBW}$ (to keep $\mathrm{P}_{\text {plat }}<30 \mathrm{cmH}_{2} \mathrm{O}$ ) was associated with a $22 \%$ reduction in ARDS mortality. However, post hoc analysis of ARDSnet data clearly showed that an absolute safe value of $P_{\text {plat }}$ does not exist [7]. Moreover, subsequent investigations have demonstrated that this volume-pressure limited protective ventilation could be associated with alveolar hyperinflation and overwhelming lung inflammation [8].

A notable strength of the work performed by Mattingley and colleagues [1] was the demonstration that VT of $6 \mathrm{ml} / \mathrm{PBW}$ targeting a $\mathrm{P}_{\text {plat }}<30 \mathrm{cmH}_{2} \mathrm{O}$ was invariably associated with a wide range of tidal recruitment when compared to TLC. The putative risks associated with these findings are either an overdistension of already aerated alveoli with higher VT, especially when higher PEEP levels are applied approaching TLC [9], or tidal hypoventilation and under-recruitment with lower VT [10]. Baseline characteristics of the current study population clearly showed that 8 of 14 patients had a BMI higher than 30 . The chest wall elastance was not 
measured; however, it is supposed to be higher in such patients and could partially explain the large differences in VT, as a dependent variable of $\mathrm{P}_{\text {plat }}$ targeted protective ventilation. Expanding on previous findings [11], we can first conclude that $\mathrm{P}_{\text {plat }}$ fails to be a valid surrogate of transpulmonary pressure in the presence of chest wall impairment. Furthermore, the H1N1 influenza outbreaks of the past 2 years may be a prime example in defining the importance of transpulmonary pressure and chest wall measurements, since numerous patients suffering severe hypoxemia were obese $[12,13]$.

Furthermore, the authors elegantly demonstrated that TLC, FRC and IC were affected by diseases requiring mechanical ventilation and by BMI. Notably, the positive relationship observed between FRC and IC allows us to speculate that IC of the 'baby lung' could be a useful parameter to set a protective ventilation strategy to minimize VILI.

Some limitations of this study should be addressed. First, the sample size of the study was very small and heterogeneous; thus, inferences from this study are limited by these potential biases. Previous studies [14] did not find any relationship between FRC and body weight, whereas FRC was increasingly affected as the disease progressed from acute lung injury to ARDS. However, as discussed above, half of the patients were obese, potentially affecting the measurements. Second, the lung volume measurements in this study were obtained at a single level of PEEP, not allowing us to assess how they could change at different PEEP levels and end expiratory lung volumes [15].

In conclusion, mechanical ventilator settings should be tailored in ARDS patients according to respiratory mechanics changes as determined by disease severity and chest wall elastance impairment. In the obese patients, $\mathrm{P}_{\text {plat }}$ could not provide a good estimation of alveolar distending pressure. In such patients, trans-pulmonary pressure - measured as the difference between $\mathrm{P}_{\text {plat }}$ and esophageal pressure - should be used to select the best combination of VT and PEEP. However, whether lung volume measurements obtained from the wash-in/washout technique are useful to tailor a protective mechanical ventilation strategy in ARDS patients remains to be determined.

\section{Abbreviations}

ARDS, acute respiratory distress syndrome; BMI, body mass index; FRC, functional residual capacity; IC, inspiratory capacity; PBW, predicted body weight; PEEP, positive end-expiratory pressure; $\mathrm{P}_{\text {plar }}$ plateau pressure; TLC, total lung capacity; VILI, ventilator-induced lung injury; VT, tidal volume.

\section{Competing interests}

The authors declare that they have no competing interests.

\section{Author details}

'The Keenan Research Centre of the Li Ka Shing Knowledge Institute of St Michael's Hospital, 30 Bond Street, Toronto, Ontario, Canada M5B 1W8.
${ }^{2}$ Interdepartmental Division of Critical Care, University of Toronto, Ontario, Canada M5B 1W8. ${ }^{3}$ Department of Anestesia and Critical Care, Ospedale S. Giovanni Battista-Molinette, corso Dogliotti 14, 10126, University of Turin, Turin, Italy.

Published: 25 March 2011

\section{References}

1. Mattingley JS, Holets SR, Oeckler RA, Stroetz RW, Buck CF, Hubmayr RD: Sizing the lung of mechanically ventilated patients. Crit Care 2011, 15:R60.

2. Ranieri VM, Suter PM, Tortorella C, De Tullio R, Dayer JM, Brienza A, Bruno F, Slutsky AS: Effect of mechanical ventilation on inflammatory mediators in patients with acute respiratory distress syndrome: a randomized controlled trial. JAMA 1999, 282:54-61.

3. Lionetti V, Recchia FA, Ranieri VM: Overview of ventilator-induced lung injury mechanisms. Curr Opin Crit Care 2005, 11:82-86.

4. Tremblay LN, Slutsky AS: Ventilator-induced injury: from barotrauma to biotrauma. Proc Assoc Am Physicians 1998, 110:482-488.

5. Zhang H, Kim YK, Govindarajan A, Baba A, Binnie M, Marco Ranieri V, Liu M, Slutsky AS: Effect of adrenoreceptors on endotoxin-induced cytokines and lipid peroxidation in lung explants. Am J Respir Crit Care Med 1999, 160:1703-1710.

6. Ventilation with lower tidal volumes as compared with traditional tidal volumes for acute lung injury and the acute respiratory distress syndrome. The Acute Respiratory Distress Syndrome Network. N Engl J Med 2000, 342:1301-1308.

7. Hager DN, Krishnan JA, Hayden DL, Brower RG: Tidal volume reduction in patients with acute lung injury when plateau pressures are not high. Am J Respir Crit Care Med 2005, 172:1241-1245.

8. Terragni PP, Rosboch G, Tealdi A, Corno E, Menaldo E, Davini O, Gandini G, Herrmann P, Mascia L, Quintel M, Slutsky AS, Gattinoni L, Ranieri VM: Tidal hyperinflation during low tidal volume ventilation in acute respiratory distress syndrome. Am J Respir Crit Care Med 2007, 175:160-166.

9. Grasso S, Fanelli V, Cafarelli A, Anaclerio R, Amabile M, Ancona G, Fiore T: Effects of high versus low positive end-expiratory pressures in acute respiratory distress syndrome. Am J Respir Crit Care Med 2005, 171:1002-1008.

10. Caironi P, Cressoni M, Chiumello D, Ranieri M, Quintel M, Russo SG, Cornejo R, Bugedo G, Carlesso E, Russo R, Caspani L, Gattinoni L: Lung opening and closing during ventilation of acute respiratory distress syndrome. Am J Respir Crit Care Med, 181:578-586.

11. Talmor D, Sarge T, Malhotra A, O'Donnell CR, Ritz R, Lisbon A, Novack V, Loring $\mathrm{SH}$ : Mechanical ventilation guided by esophageal pressure in acute lung injury. N Engl J Med 2008, 359:2095-2104.

12. Kumar A, Zarychanski R, Pinto R, Cook DJ, Marshall J, Lacroix J, Stelfox T, Bagshaw S, Choong K, Lamontagne F, Turgeon AF, Lapinsky S, Ahern SP, Smith O, Siddiqui F, Jouvet P, Khwaja K, McIntyre L, Menon K, Hutchison J, Hornstein D, Joffe A, Lauzier F, Singh J, Karachi T, Wiebe K, Olafson K, Ramsey C, Sharma S, Dodek P, et al:: Critically ill patients with 2009 influenza A(H1N1) infection in Canada. JAMA 2009, 302:1872-1879.

13. Domínguez-Cherit G, Lapinsky SE, Macias AE, Pinto R, Espinosa-Perez L, de la Torre A, Poblano-Morales M, Baltazar-Torres JA, Bautista E, Martinez A, Martinez MA, Rivero E, Valdez R, Ruiz-Palacios G, Hernández M, Stewart TE, Fowler RA: Critically III patients with 2009 influenza A(H1N1) in Mexico. JAMA 2009, 302:1880-1887.

14. Chiumello D, Carlesso E, Cadringher P, Caironi P, Valenza F, Polli F, Tallarini F, Cozzi P, Cressoni M, Colombo A, Marini JJ, Gattinoni L: Lung stress and strain during mechanical ventilation for acute respiratory distress syndrome. Am J Respir Crit Care Med 2008, 178:346-355.

15. Gattinoni L, Caironi P, Cressoni M, Chiumello D, Ranieri VM, Quintel M, Russo S, Patroniti N, Cornejo R, Bugedo G: Lung recruitment in patients with the acute respiratory distress syndrome. N Engl J Med 2006, 354:1775-1786.

\section{doi:10.1186/cc10077}

Cite this article as: Fanelli V, Ranieri VM: When pressure does not mean volume? Body mass index may account for the dissociation. Critical Care 2011, 15:143. 